\title{
The Effects of Grass-Based versus Grain-Based Feeding of Ruminants on the Human Hygienic Status, a Review
}

\author{
Tahreer M. Al-Thuwaini and Mohammed Baqur S. Al-Shuhaib* \\ Department of Animal Production, College of Agriculture, Al-Qasim Green University, Al-Qasim, Babil 51001, Iraq \\ *Corresponding author's Email: mohammed79@agre.uoqasim.edu.iq; ORCID: 0000-0002-6458-2068
}

\begin{abstract}
Ruminant meat quality is one of the important factors contributing to the recent spreading of several diseases, such as obesity, cancer, and cardiovascular problems, which have increased predominately. Feeding regiment plays an important role in the determination of the composition of fatty acids and meat quality in ruminants. This review aims to highlight the main factors that lie behind the variability of ruminant meat quality and its effect on human being's health. The reduction in grass-feeding decreases saliva levels in the ruminants, which has several consequences on the rumen, including a reduction in $\mathrm{pH}$ level, along with a reduction in the microorganism activities and conjugated linoleic acid levels. In adipose tissues, the expression of the stearoyl-CoA desaturases gene is negatively affected by the decreased conjugated linoleic acid levels in the rumen, which leads to a decreased transformation of saturated fatty acids to monounsaturated fatty acids. Therefore, the lower monounsaturated fatty acids and the parallel increase in the proportion of saturated fatty acids in the consumed meat can be associated with some human diseases. Thus, the present study provided a molecular explanation for the superiority of grass-based feeding in ruminants raised at pasture in term of production of meat with a healthier quality for consumers than those raised on grains.
\end{abstract}

Key words: Grain; Grass, Human disease, Ruminant meat, SCD enzyme

\section{INTRODUCTION}

Ruminant meat plays a key role in human nutrition, as it provides an inevitable source for high-quality protein (Quiñones et al., 2017). Moreover, it is a proven reservoir for essential micronutrients and several bioactive lipids (Shingfield et al., 2013). On the other hand, meat is a main source of fat in the diet and particularly Saturated Fatty Acids (SFA), (Coutinho et al., 2014) which have been related to the recent spreading of several diseases in humans, such as Cardiovascular Diseases (CVDs), obesity, diabetes, cancer, neurological and skin damages (Makkar and Beever, 2013; Savoini et al., 2016; Hilmia et al., 2017; Temple, 2018). Atherosclerotic complications are primarily responsible for elevated morbidity and mortality in many people around the world (Mansour and Ajeel, 2013). It is estimated that 17.5 million individuals die from CVDs annually, accounting for $31 \%$ of all deaths worldwide (WHO, 2016). Impaired insulin sensitivity has been reported due to saturated fats which pose specific lipotoxicity to pancreatic $\beta$ cells. Thus, replacing SFA with Monounsaturated Fatty Acids (MUFAs) has a role in the improvement of lipoprotein and glycemic levels in individuals with type 2 diabetes (De Souza et al., 2015). However, several factors related to feeding regiment have been found to have various effects on ruminant meat quality by playing a crucial role in the determination of meat content (Priolo et al., 2001). The nutrition of cattle and sheep has a considerable impact on the deposition of intramuscular fat that has a remarkable effect on human health (Popova et al., 2008). The content of MUFA in intramuscular fat is substantially higher for grass-fed steers as compared to steers offered grass silage and/or concentrates (Nieto and Ros, 2012). The higher proportion of MUFA to SFA enhances both meat quality and feeding value of animal products (Gamarra et al., 2018). On the other hand, the Stearoyl-CoA Desaturases $(S C D)$ gene encodes an enzyme that transforms SFA into MUFA in the adipose tissues of ruminants (Tian et al., 2017) and a positive correlation has been observed between MUFA and SCD expression in ruminants (Costa et al., 2013). Although the benefits of grass nutrition on ruminant meat quality and its positive consequences on human health has been described (Pighin et al., 2016), little information is known about ruminant nutrition through what mechanism affects the meat quality. Furthermore, there is a lack of data regarding the contributing effect of biochemical molecules on human health. Therefore, this review aims to describe the main factors that cause variability in several meat-controlling molecules in the ruminants, their consequent effect on ruminant meat, and their eventual effects on human health. 


\section{Effects of saturated fatty acids on human health}

The Fatty Acid (FA) composition of dietary lipids and its consequences on meat quality have gained a lot of attention due to its effect on human health (Cho et al., 2010). It has been demonstrated that higher consumption of SFA is associated with diminished insulin sensitivity, hyperglycemia, increasing the risk of metabolic syndromes and cancers such as prostate and breast carcinomas (Khan et al., 2010; Alisson-Silva et al., 2016; Savoini et al., 2016). Furthermore, excessive consumption of ruminant meat, which is a major source of medium-chain SFA and trans FA in the human diet, is considered a risk factor for heart disease (Shingfield et al., 2013). Red meat is also characterized by a particular SFA profile that has been linked to carcinogenesis and CVD (Quiñones et al., 2017). For instance, beef contains several damaging SFAs, such as myristic and palmitic acids that are assumed to be dangerous for the heart, because it raises the serum cholesterol concentrations by four to six folds (de Lemos et al., 2017).

\section{Impacts of polyunsaturated fatty acids and conjugated linoleic acid on human health}

The recommended proportion of PUFA to SFA in ruminant meat should be 0.4 or higher (Wood et al., 2003). In this context, changing FA compositions by decreasing concentrations of PUFA and increasing levels of SFA leads to decrease the PUFA: SFA ratio in red blood cell membranes, which may be linked to lower membrane fluidity, as seen in the chronic diseases (Ristić-Medić et al., 2013). On the other hand, the consumption of meat with an imbalanced ratio of n-6:n-3 PUFA can be a risk factor for CVDs, resulting in blood clots and possibly leading to a heart attack (Wood et al., 2003). Furthermore, n-6:n-3 PUFA may also be associated with the progression of carcinogenesis (Azrad et al., 2013). Meanwhile, it has been demonstrated that ruminant meat contains a beneficial ratio of $n-6: n-3$ PUFA, that is below 4, especially when those have consumed grass-based diets (Pighin et al., 2016). More grazing leads to a higher percentage of omega-3 FA, CLA, vitamin E, $\beta$-carotene (Van Elswyk et al., 2014), vitamin A and also a low ratio of n-6:n-3 PUFA in ruminant meats which makes it highly desirable for consumption (Simopoulos, 2016). Beef from pasture-finished steers contains greater levels of n-3 PUFA in comparison to concentrate-finished steers (Pighin et al., 2016). High levels of omega-3 long-chain PUFA (n-3 LC-PUFA) in the diet plays a major role in preventing several diseases, including diabetes, atherosclerosis, and arthritis (Widmann et al., 2011), through inhibition of platelet aggregation, microbial growth (Desbois and Lawlor, 2013), and prevention of the blood clot formation (Phang et al., 2013). Interestingly, a lower incidence of depression, age-related memory loss, and developing Alzheimer's is linked to higher consumption of n-3 LC-PUFA (Wani et al., 2015).

CLA synthesized by microorganisms in the rumen as a byproduct (Arshad et al., 2018), holds considerable benefits for human health. It is believed that the consumption of CLA is beneficial to health because of its ability to increase lean muscle mass while decreasing body fat. It has been suggested that CLA has therapeutic potentials with regard to insulin resistance and hyperlipidemia which are key characeristics of type 2 diabetes (Molony et al., 2004). This relation has recently been explained by the ability of CLA to enhance insulin sensitivity (Cho et al., 2016). Therefore, it was observed that increased CLA has a strong association with anticancer (Peng et al., 2010), anti-adipogenic (Maleki et al., 2015), anti-atherosclerotic properties (De Hartigh, 2019), and cardioprotective effects (Parodi, 2009).

\section{Stearoyl-CoA Desaturases effects on human health}

The $S C D$ gene product is a major enzyme for controlling intracellular FA composition by stimulating the desaturation of SFA, thereby resulting in the conversion of SFA to MUFA in the adipose tissues of ruminants (Tian et al., 2017). Genetic groups of ruminants have shown significant differences in the activity of the $S C D$ gene product (Ivanović et al., 2016). In different organisms, there are five variants of $S C D$ genes that are known as, SCD1-SCD5, placed at several chromosomal positions (Furqon et al., 2017). Furthermore, the expression of $S C D$ in the muscle tissues can be affected by nutrition composition, especially n-3 PUFA contents. The level of $S C D$ gene expression plays a key role in terminal adipocytes differentiation as adipogenesis has been found to be greatly induced by $S C D$ gene expression (Madsen et al., 2005). This pattern of $S C D$-induced adipocytes differentiation leads to a consequent accumulation of intramuscular fat, which points to the link between the gene expression of $S C D$ and increasing FA deposition in the ruminant muscle (Costa et al., 2013). However, hormones and several nutrients including FAs, carbohydrates, and cholesterol, have been recognized as a potent modulator of the $S C D$ gene expression. Moreover, the expression of the $S C D$ is positively related to elevated CLA and MUFA contents, which entails considerable impacts on human health (Barton et al., 2010).

\section{The impacts of grass-based versus grain-based feeding on the rumen environment}

In the ruminant digestive system, the composition of the FAs present in the rumen is affected by the rumen microorganisms and ruminal $\mathrm{pH}$ (Kashani, 2015). SFA, like palmitic (C16:0) and stearic (C18:0) acids, pass through the rumen unaltered, while the Unsaturated Fatty Acid (UFA) is subjected to biohydrogenation and converted to SFA to decrease the toxic effects of dietary UFA on the microorganism's growth and production of CLA as a byproduct (Shingfield et al., 2013). LC-PUFA has also been reported to have differential toxicity and inhibitory effects on rumen 
microorganisms (Lourenco et al., 2010). Thus, the conversion of UFA to SFA, or biohydrogenation, in the ruminants represents a major human health issue. It is noteworthy that the high forage proportion in the grass-based feeding causes higher secretion of saliva (Figure 1A), ensuring higher rumen $\mathrm{pH}$ (Lee et al., 2016), and thus, strengthening the effect of lipolysis and/or biohydrogenation (Scollan and Enserb, 2003). Grass-feeding increases the content of CLA due to the biohydrogenation of the PUFA linolenic acid in the rumen that has a twofold higher concentration in the digestion of the pasture-fed steers, as compared to corn-fed steers (Smith et al., 2009). Regarding grain-based feeding, the biohydrogenation process was found to be inhibited by a decrease in the ruminal $\mathrm{pH}$ and ultimately growth inhibition of the CLA-producing bacteria (Wood et al., 2008) (Figure 1B). The reduction in the pH values is typically linked with this sort of diet, as the presence of concentrated food components reduces lipolysis, which is a fundamental step in biohydrogenation (Menezes et al., 2010). If ruminal biohydrogenation of UFA can be controlled, it may be possible to enhance the quality of ruminant meats via generally increasing UFA, CLA, and n-3 FAs in particular. Most of the alimentary FA are UFAs (oleic acid [C18:1 cis-9]; linolenic acid [C18:3n-3], and linoleic acid [C18:2n-6]) that are converted to SFA (C18:0) in the rumen by biohydrogenation, with a plethora of CLA isomers throughout the process of isomerization (Dewanckele et al., 2018). Therefore, meat products supplied by more isomers of CLA, result in higher CLA concentrations in consumed meat (Silveira et al., 2007).

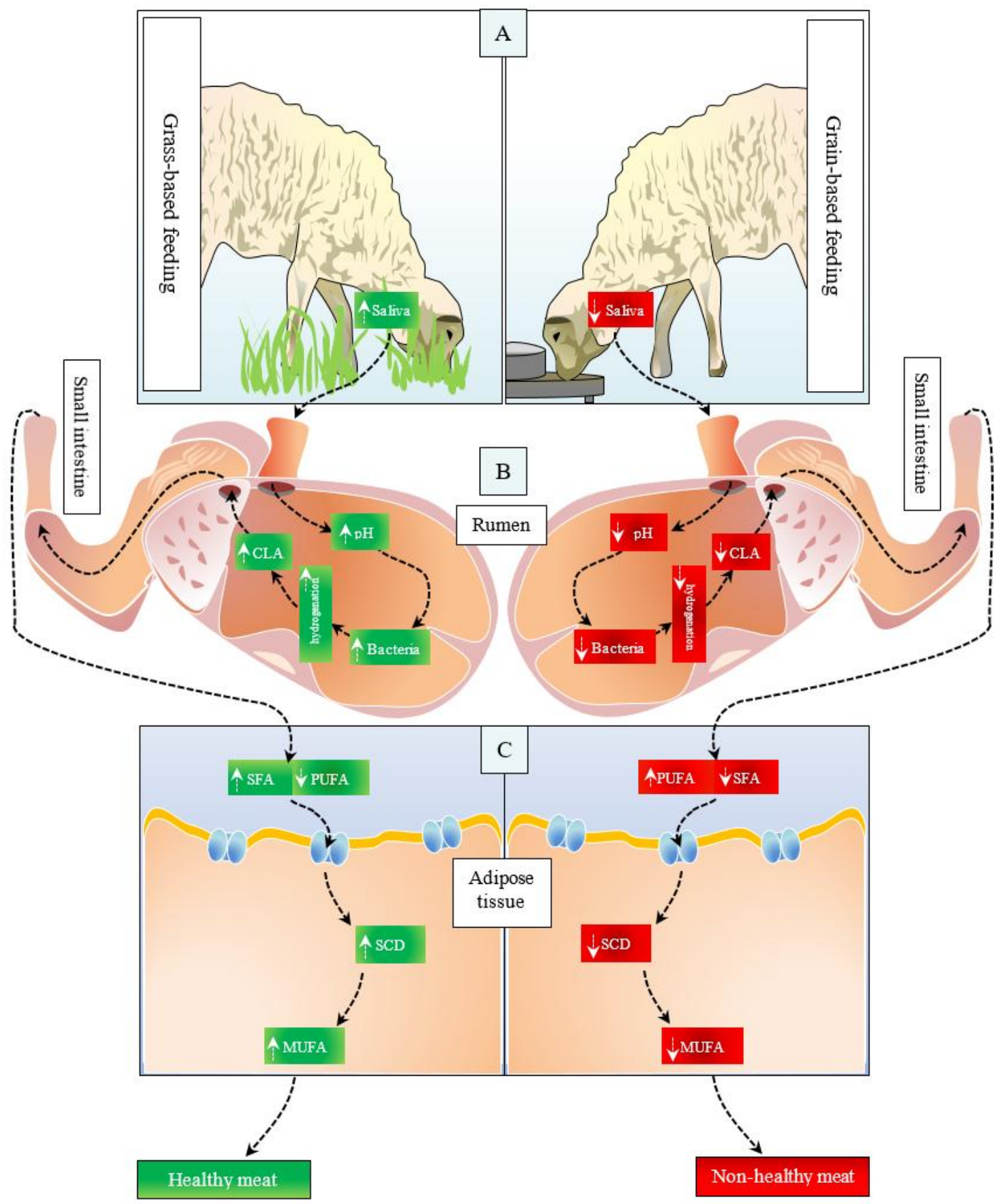

Figure 1. Comparison between grass-based versus grain-based ruminant feeding routes. A, B and C refer to impacts of consumed feed on saliva, rumen, and adipose tissues, respectively. 


\section{The impacts of grass-based versus grain-based feeding on adipose tissue}

About $70-80 \%$ of FAs were accumulated in the tissues as CLA during the ruminal biohydrogenation of dietary linoleic acid (Lobo et al., 2014). The levels of rumenic acid, the most important CLA isomer, along with arachidonic (C20:4c5) and phytanic acid, are at least three times higher in the muscles of grass-fed animals in comparison to grainfed animals (Moholisa et al., 2018). The increased concentrations of SFA and decreased concentrations of PUFA in ruminant tissues is due to a higher ruminal $\mathrm{pH}$ and consequently higher biohydrogenation rate in the rumen (Hughes, 2011). However, lower gene expression of the $S C D$ as a result of an increased level of PUFA has been reported in different animal species and tissues (Conte et al., 2012). Thus, inhibiting the biohydrogenation pathway could increase the levels of PUFA in tissues and lead to a reduction in the gene expression of $S C D$ in ruminants (Figure 1C). Moreover, PUFA suppresses the expression of lipogenic genes by inhibiting proteolysis of sterol regulatory element-binding protein 1 in the Golgi apparatus (Jacobs et al., 2013). Therefore, a nutritional regimen that increases PUFA absorption in the muscles will reduce meat quality. A parallel relationship of n-6: n-3 PUFA proportion with levels of $S C D$ gene expression and in turn, CLA production in the muscle tissue, was reconfirmed (Ebrahimi et al., 2018).

The higher the expression of the $S C D 1$ gene in grass-feeding is associated to the elevated converting ratio of MUFAs to SFAs, increased levels of phospholipid membrane composition, fat metabolism, and adiposity (Hilmia et al., 2017). Thus, the high proportion of MUFA to SFA enhances both the quality and feeding value of animal products. The correlation analysis among oleic acid proportion and CLA percentage, with the levels of $S C D$ expression in ruminants, appears to have been effective (de Castro et al., 2013). Positive correlations between $S C D$ expression and FA content is observed, particularly for total FAs, MUFA, and c9,t11-CLA, while lower SCD expression in adipose tissues is detected in Holstein-Friesian cows and mature culled cows when fed with PUFA (Gamarra et al., 2018). Thus, imparting nutrition for animals with PUFA enriched diets results in a lower expression $S C D$ gene, which appears to be due to the inhibitory role of PUFA on the promotion of the $S C D$ gene in the liver and adipose tissues (Benítez et al., 2017)

\section{CONCLUSION}

In conclusion, several factors affect the meat quality of ruminants and lead to sanitation problems for human health. In the last 60 years, reduction in the pasture quality due to a lack of vegetation and the reliance of the farmer to the use of grains for ruminant nutrition caused a decrease in CLA levels, reduced $S C D$ activity in tissues, and decreased MUFA (or increased SFA) levels in ruminant meat which are involved in the pathogenesis of several chronic human diseases. Conversely, high expression of the $S C D 1$ gene in grass-fed ruminants is effective in meat production with a highly favorable quality for the consumers' health.

\section{DECLARATIONS}

\section{Competing interests}

The authors have declared that no competing interest exists.

\section{Consent to publish}

All authors gave their informed consent prior to their inclusion in the study.

\section{Authors' contributions}

TM Al-Thuwaini designed the main idea and wrote the review. MBS Al-Shuhaib revised the review and drew the schematic diagram presented in figure 1.

\section{REFERENCES}

Alisson-Silva F, Kawanishi K and Varki A (2016). Human risk of diseases associated with red meat intake, analysis of current theories and proposed role for metabolic incorporation of a non-human sialic acid. Molecular Aspects of Medicine, 51: 16-30. Doi:https://doi.org/10.1016/j.mam.2016.07.002

Arshad MS, Sohaib M, Ahmad RS, Nadeem MT, Imran A, Arshad MU, Kwon JH and Amjad Z (2018). Ruminant meat flavor influenced by different factors with special reference to fatty acids. Lipids in Health and Disease, 17(1): 223. Doi:https://doi.10.1186/s12944-018-0860-z

Azrad M, Turgeon C and Demark-Wahnefried W (2013). Current evidence linking polyunsaturated fatty acids with cancer risk and progression. Frontiers in Oncology, 4: 224. Doi:https://doi.org/10.3389/fonc.2013.00224.

Barton L, Kott T, Bures D, Rehak D, Zahradkova R and Kottova B (2010). The polymorphisms of stearoyl-CoA desaturase (SCD1) and sterol regulatory element binding protein - 1 (SREB - 1) genes and their association with the fatty acid profile of muscle and subcutaneous fat in Fleckvieh bulls. Meat Science, 85: 15-20. Doi:https://doi.org/10.1016/j.meatsci.2009.11.016.

Benítez R, Núñez Y and Óvilo C (2017). Nutrigenomics in farm animals. Journal of Investigative Genomics, 4(1): p.00059. Doi:https://doi.org/10.15406/jig.2017.04.00059 
Cho K, Song Y and Kwon D (2016). Conjugated linoleic acid supplementation enhances insulin sensitivity and peroxisome proliferator-activated receptor gamma and glucose transporter type 4 protein expression in the skeletal muscles of rats during endurance exercise. Iranian Journal of Basic Med Science, 19(1): 20-27.

Cho YM, Lee SH, Park EW, Kim NK, Lim D, Kim KH, Park BY, Lee CS, Oh SJ, Kim TH and Yoon D (2010). Association of $867 \mathrm{G}>\mathrm{C},-877 \mathrm{Gdel}$, and Exon $5 \mathrm{G}>\mathrm{T}$ polymorphisms in the Stearoyl-CoA Desaturase $(S C D)$ gene with fatty acid composition in the M. longissimus dorsi muscle of Hanwoo (Korean Cattle). Korean Journal of Food Science Animal Resources, 30(4): 655660. Doi: https://doi.org/10.5851/kosfa.2010.30.4.655

Conte G, Jeronimo E, Serra A, Bessa RJB and Mele M (2012). Effect of dietary polyunsaturated fatty acids on Stearoyl CoADesaturase gene expression in intramuscular lipids of lamb, Italian Journal of Animal Science, 11: e79. Doi:https://doi.org/10.4081/ijas.2012.e79

Costa AS, Silva MP, Alfaia CP, Pires VM, Fontes CM, Bessa RJ and Prates JA (2013). Genetic background and diet impact beef fatty acid composition and Stearoyl-CoA Desaturase mRNA expression. Lipids, 48(4): 369-381. Doi:https://doi.org/10.1007/s11745013-3776-4

Coutinho MDS, Morais MDG, Coelho RG, Alves FV, Fernandes HJ, Ítavo CCBF, Comparin MAS and Ribeiro CB (2014). Lipid profile and cholesterol in meat cuts of ewe lambs fed different levels of concentrate. Semina-Cienc. Agrarias, 35(6): $3355-3365$. Doi:https://doi.org/10.5433/1679-0359.2014v35n6p3355

De Castro Barra PM, Castro RDJC, de Oliveira PL, Aued-Pimentel S, da Silva SA and de Oliveira MAL (2013). An alternative method for rapid quantitative analysis of majority cis-trans fatty acids by CZE. Food Research International, 52(1): 33-41. Doi:https://doi.org/10.1016/j.foodres.2013.02.044

De Hartigh LJ (2019). Conjugated linoleic acid effects on cancer, obesity, and atherosclerosis, a review of pre- clinical and human trials with current perspectives. Nutrients, 11(2). pii. E370. Doi:https://doi.org/10.3390/nu11020370

De Lemos MVA, Pereira ASC, Regatieri IC, Feitosa FLB and Baldi F (2017). Genetic factors that determine the meat fatty acids composition. Fatty Acids Angel. Catala., IntechOpen. Doi:https//dx.doi.org/10.5772/67693

De Souza RJ, Mente A, Maroleanu AI, Cozma AI, Ha V, Kishibe T, Uleryk E, Budylowski P, Schünemann H, Beyene J and Anand SS (2015). Intake of saturated and trans unsaturated fatty acids and risk of all cause mortality, cardiovascular disease, and type 2 diabetes: systematic review and meta-analysis of observational studies. BMJ 351, h3978. Doi:https://doi.org/10.1136/bmj.h3978

Desbois AP and Lawlor KC (2013). Antibacterial activity of long-chain polyunsaturated fatty acids against Propionibacterium acnes and Staphylococcus aureus. Marine drugs, 11(11): 4544-4557. Doi:https://doi.org/10.3390/md11114544

Dewanckele L, Vlaeminck B, Hernandez-Sanabria E, Ruiz-González A, Debruyne S, Jeyanathan J and Fievez V (2018). Rumen biohydrogenation and microbial community changes upon early life supplementation of 22, 6 n-3 enriched microalgae to goats. Frontiers in Microbiology, 9: 573. Doi:https://doi.org/10.3389/fmicb.2018.00573

Ebrahimi M, Rajion MA, Jafari S, Jahromi MF, Oskoueian E, Sazili AQ, Goh YM and Ghaffari MH (2018). Effects of dietary n-6, n-3 polyunsaturated fatty acid ratios on meat quality, carcass characteristics, tissue fatty acid profiles, and expression of lipogenic genes in growing goats. PloS one, 13(8): p.e0188369. Doi:https://doi.org/10.1371/journal.pone.0188369

Furqon A, Gunawan A, Ulupi N, Suryati T and Sumantri C (2017). Expression and association of SCD gene polymorphisms and fatty acid compositions in chicken cross. Media Peternakan, 40(3): 151-157. Doi:https://doi.org/10.5398/medpet.2017.40.3.151

Gamarra D, Aldai N, Arakawa A, Barron LJR, López-Oceja A, de Pancorbo MM and Taniguchi M (2018). Distinct correlations between lipogenic gene expression and fatty acid composition of subcutaneous fat among cattle breeds. BMC Veterinary Research, 14(1): 167. Doi:https://doi.org/10.1186/s12917-018-1481-5

Hilmia N, Noor RR, Sumantri C, Gurnadi RE and Priyanto R (2017). Polymorphism of stearoyl-CoA desaturase (SCD1) gene in Indonesian local cattle. Journal of the Indonesian Tropical Animal Agriculture, 42(1): 1-5. Doi: https://doi.org/10.14710/jitaa.42.1.1-5

Hughes J (2011). The effect of dietary omega-3 and -6 polyunsaturated fatty acids on ovine ovarian function and the pre-implantation embryo. PhD Thesis, University of Nottingham.

Ivanović S, Pavlović I and Pisinov B (2016). The quality of goat meat and its impact on human health. Biotechnology in Animal Husbandry, 32(2): 111-122. Doi:https://doi.10.2298/BAH1602111I

Jacobs AAA, Dijkstra J, Liesman JS, Vandehaar MJ, Lock AL, van Vuuren AM, Hendriks WH and van Baal J (2013). Effects of short-and long-chain fatty acids on the expression of stearoyl-CoA desaturase and other lipogenic genes in bovine mammary epithelial cells. Animal, 7(9): 1508-1516. Doi:https://doi.org/10.1017/S175173111300061X

Kashani A (2015). Genetic and dietary enhancement of n-3 fatty acids in sheep meat. PhD Thesis, University of Tasmania, Australia. Doi:https://doi.org/10.13140/RG.2.1.3462.9364

Khan N, Afaq F and Mukhtar H (2010). Lifestyle as risk factor for cancer: evidence from human studies. Cancer letters, 293(2): 133143. Doi:https://doi.org/10.1016/j.canlet.2009.12.013

Lee BH, Nejad JG, Kim BW, Ohh SJ and Sung KI (2016). Fatty acid profile of meat, diurnal changes in volatile fatty acids, rumen fluid parameters, and growth performance in Korean native (Hanwoo) steers fed high-and low-forage diets supplemented with chromium-methionine. Revista Brasileira de Zootecnia, 45(8): 483-488. Doi:https://doi.org/10.1590/S180692902016000800009

Lobo AMBO, Bomfim MAD, Faco O, Junior GAF, Ponciano MF and Lobo RNB (2014). Intramuscular fat and fatty acid profile of muscle of lambs finished in irrigated pasture. Journal of Applied Animal Research, 42 (1): 110-117. Doi:https://doi.org/10.1080/09712119.2013.822810

Lourenco M, Ramos-Morales E and Wallace RJ (2010). The role of microbes in rumen lipolysis and biohydrogenation and their manipulation. Animal, 4(7): 1008-1023. Doi: https://doi.org/10.1017/S175173111000042X.

Madsen L, Petersen RK and Kristiansen K (2005). Regulation of adipocyte differentiation and function by polyunsaturated fatty acids. Biochim Biophys Acta 1740: 266-86. Doi:https://doi.org/10.1016/j.bbadis.2005.03.001

To cite this paper: Al-Thuwaini TM and Al-Shuhaib MBS (2019). The Effects of Grass-Based versus Grain-Based Feeding of Ruminants on the Human Hygienic Status, a 
Makkar HPS and Beever D (2013). Optimization of feed use efficiency in ruminant production systems. Proceedings of the FAO Symposium, 27 November 2012, Bangkok, Thailand. FAO Animal Production and Health Proceedings, No. 16. Rome, FAO and Asian-Australasian Association of Animal Production Societies.

Maleki E, Kafilzadeh F, Meng GY, Rajion MA and Ebrahimi M (2015). The effect of breed on fatty acid composition of subcutaneous adipose tissues in fat-tailed sheep under identical feeding conditions. South African Journal of Animal Science, 45(1): 12-19. Doi:http://dx.doi.org/10.4314/sajas.v45i1.2

Mansour AA and Ajeel NAH (2013). Atherosclerotic cardiovascular disease among patients with type 2 diabetes in Basrah. World Journal of Diabetes, 15, 4(3): 82-87. Doi:https://doi.org/10.4239/wjd.v4.i3.82

Menezes LFGD, Kozloski GV, Restle J, Brondani IL, Pazdiora RD and Cattelam J (2010). Profile of ingested fatty acids and in the duodenal digest of steers fed different diets. Revista Brasileira de Zootecnia, 39(11): $2502-2511$. Doi:https://doi.org/10.1590/S1516-35982010001100025

Moholisa E, Strydom PE and Hugo A (2018). The effect of beef production system on proximate composition and fatty acid profile of three beef muscles. South African Journal of Animal Science, 48(2): 295-306. Doi:https://doi.org/10.4314/sajas.v48i2.10

Moloney F, Yeow TP, Mullen A, Nolan JJ and Roche HM (2004). Conjugated linoleic acid supplementation, insulin sensitivity, and lipoprotein metabolism in patients with type 2 diabetes mellitus. American Journal of Clinical Nutrition, 80(4): 887-95. Doi: https://doi.org/10.1093/ajcn/80.4.887

Nieto G and Ros G (2012). Modification of fatty acid composition in meat through diet: effect on lipid peroxidation and relationship to nutritional quality-a review. In Lipid Peroxidation. InTech. Doi:https://doi.org/10.5772/51114

Parodi PW (2009). Has the association between saturated fatty acids, serum cholesterol and coronary heart disease been over emphasized? International Dairy Journal, 19(6-7): 345-361. Doi:https://doi.10.1016/j.idairyj.2009.01.001

Peng YS, Brown MA, Wu JP and Liu Z (2010). Different oilseed supplements alter fatty acid composition of different adipose tissues of adult ewes. Meat Science, 85: 542-549. Doi:https://doi.10.1016/j.meatsci.2010.03.003

Phang M, Lincz LF and Garg M (2013). Eicosapentaenoic and docosahexaenoic acid supplementations reduce platelet aggregation and hemostatic markers differentially in men and women. Journal of Nutrition, 143(4): 457-463. Doi:https://doi.10.3945/jn.112.171249.

Pighin D, Pazos A, Chamorro V, Paschetta F, Cunzolo S, Godoy F, Messina V, Pordomingo A and Grigioni G (2016). A contribution of beef to human health: a review of the role of the animal production systems. The Scientific World Journal, 2016, 8681491. Doi:https://doi.org/10.1155/2016/8681491

Popova T, Marinova P, Banskalieva V and Vasileva V (2008). Content and fatty acid composition of different fat depots of lambs receiving fish oil supplemented diet. Bulgarian Journal of Agricatural. Science, 14(1), 100-107.

Priolo A, Didier MD and Agabrie J (2001). Effects of grass feeding systems on ruminant meat color and flavor. a review. Animal Research, 50(3): 185-200. Doi:https://doi.org/10.1051/animres:2001125

Quiñones J, Bravo S, Calvo JH and Sepúlveda N (2017). Genetic polymorphism in meat fatty acids in araucano creole sheeps. Journal of Animal and Plant Sciences 27(3): 743-746.

Ristić-Medić D, Vučić V, Takić M, Karadžić I and Glibetić M (2013). Polyunsaturated fatty acids in health and disease. Journal of Serbian Chemical Society, 78(9): 1269-1289. Doi:https://doi.org/10.2298/JSC130402040R

Savoini G, Farina G, Dell'Orto V and Cattaneo D (2016). Through ruminant nutrition to human health, role of fatty acids. Advances in Animal Biosciences 7(2): 200-207. Doi:https://doi.org/10.1017/S2040470016000133

Scollan N, Lee M and Enserb M (2003). Biohydrogenation and digestion of long chain fatty acids in steers fed on Lolium perenne bred for elevated levels of water-soluble carbohydrate. Animal Research, 52(6): 501-511. Doi:https://doi.org/10.1051/animres:2003040

Shingfield KJ, Bonnet M and Scollan ND (2013). Recent developments in altering the fatty acid composition of ruminant-derived foods. Animal, 7 (s1): 132-162. Doi:https://doi.org/10.1017/S1751731112001681.

Silveira M-B, Carraro R, Monereo S and Tebar J (2007). Conjugated linoleic acid (CLA) and obesity. Public Health Nutrition, 10(10A): 1181-1186. Doi:https://doi.org/10.1017/S1368980007000687

Simopoulos AP (2016). An increase in the omega-6/omega-3 fatty acid ratio increases the risk for obesity. Nutrients, 8(3): 128. Doi:https://doi.org/10.3390/nu8030128

Smith SB, Gill CA, Lunt DK and Brooks MA (2009). Regulation of fat and fatty acid composition in beef cattle. Asian-Austraian Journal of Animal Science, 22 (9): 1225-1233.

Temple NJ (2018). Fat, Sugar, whole grains and heart disease: 50 years of confusion. Nutrients, 10(1): 39. Doi:https://doi:10.3390/nu10010039

Tian P, Luo Y, Li X, Tian J, Tao S, Hua C, Geng Y, Ni Y and Zhao R (2017). Negative effects of long-term feeding of high-grain diets to lactating goats on milk fat production and composition by regulating gene expression and DNA methylation in the mammary gland. Journal of Animal Science and Biotechnology, 8(1): 74. Doi:https://doi.org/10.1186/s40104-017-0204-2

Van Elswyk ME, and McNeill SH (2014). Impact of grass/forage feeding versus grain finishing on beef nutrients and sensory quality, The US experience. Meat Science, 96(1): 535-540. Doi:https://doi.org/10.1016/j.meatsci.2013.08.010

Wani AL, Bhat SA and Ara A (2015). Omega-3 fatty acids and the treatment of depression, a review of scientific evidence. Integrative Medicine Research, 4(3): 132-141. Doi:https://doi.10.1016/j.imr.2015.07.003

Widmann P, Nuernberg K, Kuehn C and Weikard R (2011). Association of an ACSL1 gene variant with polyunsaturated fatty acids in bovine skeletal muscle. BMC Genetics, 12, 96. Doi:https://doi.org/10.1186/1471-2156-12-96

Wood JD, Enser M, Fisher AV, Nute GR, Sheard PR, Richardson RI, Hughes SI and Whittington FM (2008). Fat deposition, fatty acid composition and meat quality, a review. Meat Science, 78: 343-358. Doi:https://doi.org/10.1016/j.meatsci.2007.07.019

To cite this paper: Al-Thuwaini TM and Al-Shuhaib MBS (2019). The Effects of Grass-Based versus Grain-Based Feeding of Ruminants on the Human Hygienic Status, a 
Wood JD, Richardson RI, Nute GR, Fisher AV, Campo MM, Kasapidou E, Sheard PR and Enser M (2003). Effects of fatty acids on meat quality, a review. Meat Science, 66: 21-32. Doi:https://doi.org/10.1016/S0309-1740(03)00022-6

World Health Organization (WHO) (2016). Hearts: technical package for cardiovascular disease management in primary health care. Geneva, Switzerland: World
cardiovascular_diseases/hearts/Hearts_package.pdf

Health Organization. Available

at:http://www.who.int/ 